\title{
Verbal short-term memory shows a specific association with receptive but not productive vocabulary measures in Down syndrome
}

\author{
S. Majerus ${ }^{1,2} \&$ K. Barisnikov ${ }^{3}$ \\ I Psychology E Neuroscience of Cognition Research Unit, Université de Liège, Liège, Belgium \\ 2 Fonds de la Recherche Scientifique FNRS, Brussels, Belgium \\ 3 Department of Psychology, Université de Genève, Geneva, Switzerland
}

\begin{abstract}
Background Verbal short-term memory (STM) capacity has been considered to support vocabulary learning in typical children and adults, but evidence for this link is inconsistent for studies in individuals with Down syndrome (DS). The aim of this study was explore the role of processing demands on the association between verbal STM and vocabulary measures in DS, by comparing receptive vocabulary measures with high STM processing demands to productive vocabulary measures with low STM processing demands.

Method Forty-seven adults with Down syndrome were administered receptive vocabulary and productive vocabulary tasks, as well as measures of verbal STM abilities and intellectual efficiency. Results Bayesian regression analyses showed that verbal STM abilities were strongly and specifically associated with receptive vocabulary measures but not productive lexical abilities after controlling for intellectual efficiency, and this is despite the fact that vocabulary abilities as measured by receptive and productive vocabulary tasks were closely associated.
\end{abstract}

Correspondence: Steve Majerus, PhD, Psychology \& Neuroscience of Cognition Research Unit (PsyNCog), Université de Liège, Boulevard du Rectorat, B33, 4000 Liège, Belgium. Tel. 0032 43664656 (e-mail: smajerus@ulg.ac.be)
Conclusions In Down syndrome, verbal STM abilities may be predictive of specific task demands associated with receptive vocabulary tasks rather than of vocabulary development per se.

Keywords Down syndrome, productive vocabulary, receptive vocabulary, short-term memory

\section{Introduction}

Verbal short-term memory (STM), and especially STM for serial order, has been shown to be closely associated with lexical learning abilities and knowledge in typical development. However, this association has been questioned in Down syndrome (DS). The aim of the present study is to clarify the association of verbal STM and vocabulary knowledge in DS, by examining both receptive and productive vocabulary abilities and by controlling for the influence of other cognitive abilities that may affect performance on STM and vocabulary tasks, such as attention and inhibitory abilities.

In typical development, a number of studies have shown a consistent association between estimates of verbal STM and vocabulary knowledge, especially in younger children (e.g. Gathercole et al. 1992; Service 1992; Gathercole et al. 1994; Avons et al. 1998). This association is still visible in adults, participants with 
high verbal STM abilities showing faster learning in novel vocabulary learning tasks than adults with lower verbal STM abilities (Papagno et al. I99I; Majerus et al. 2008). In the framework of the phonological loop model, the association between performance on STM tasks and vocabulary development is considered to reflect the importance of temporary phonological storage capacity for forming new long-term phonological lexical representations (e.g. Baddeley et al. 1998). Although the nature of this association is difficult to interpret due to the fact that verbal STM tasks are themselves strongly influenced by available language knowledge (Hulme et al. I99I; Gathercole et al. 1999), more recent studies have shown that verbal STM tasks that minimise language processing requirements are strong predictors of receptive vocabulary knowledge. Especially tasks maximising the retention of serial order information, by using memory lists composed of highly familiar and predictable memoranda and by only varying the serial position in which the memoranda appear, are associated with vocabulary knowledge in both children and adults; this association is more robust than for phonological item STM tasks that involve recall of non-word stimuli with minimal serial order processing requirements (Majerus et al. 2006; Majerus et al. 2008; Leclercq \& Majerus 2010). The theoretical interpretation of these findings is that the ability to temporarily maintain sequence information via a dedicated short-term storage system for order information allows unfamiliar phoneme sequences, which define a novel word, to be maintained and replayed in correct order during the learning process, thereby increasing the strength of the new lexical representation being created in the language knowledge base; on the other hand, the linguistic system is considered to allow for the encoding of familiar item information (Gupta 2003; Majerus et al. 2006). This distinction between item and serial order processing levels is based on an increasing number of studies showing dissociations between verbal item STM and serial order STM abilities, and observing an impact of linguistic knowledge on item but not order STM (refer to Majerus (2013) for a review).

Down syndrome results from a chromosome $2 \mathrm{I}$ trisomy and is characterised by poor verbal abilities, at both language and STM levels, as compared with visuo-spatial abilities (Chapman 2003; Brock \& Jarrold 2004, 2005; Hick et al. 2005; Chapman et al.
2006). This has led a number of authors to consider that DS reflects neurogenetic evidence for a close relationship between verbal STM and language development (Chapman et al. 2002; Jarrold et al. 2009). Verbal STM abilities in individuals with DS indeed predict later receptive vocabulary abilities or performance in a novel word learning task (Laws \& Gunn 2004; Jarrold et al. 2009). On the other hand, vocabulary abilities often tend to be superior to what might be expected on the basis of the very limited verbal STM abilities. Iacono et al. (2010) reported a mean receptive vocabulary age of 5.2 years in adults with DS, while mean digit span was only 2.3 (digit span is about 4 in typically developing 5-year-old children; Gathercole et al. I997) (see Jarrold et al. 2002). Mosse and Jarrold (2OII) observed that novel word learning abilities can be preserved in children and adults with DS, despite the existence of severe verbal STM limitations. In the same vein, Naess et al. (20I5) did not observe any specific longitudinal relationship between verbal STM measures and later vocabulary knowledge in children with DS, after controlling for initial vocabulary knowledge.

In order to better understand the link between STM abilities and vocabulary learning in DS, it is important to consider task demands of the vocabulary and verbal STM measures typically used in studies with DS. First, some of the vocabulary measures may have inherent STM processing demands. The most typically used task for assessing vocabulary knowledge is the Peabody Picture Vocabulary Test (PPVT; Dunn \& Dunn I98I). This task requires matching of one auditorily presented word to one out of four pictures; STM processing is necessary here for the retention of the target word, especially when the phonological form cannot be immediately matched to a long-term lexical and semantic representation; this stage may already be problematic for individuals with DS whose STM spans rarely exceed a span size of 2 . Furthermore, the target word needs to be compared against the lexical labels elicited by the four pictures, leading to up to four temporary representations that need to be held and compared in STM. Thus, the association between verbal STM and receptive vocabulary knowledge may be influenced by the intrinsic STM processing demands of the receptive vocabulary tasks (Mosse \& Jarrold 20II).

The aim of the present study was to re-assess the association between verbal STM and vocabulary

(C) 2017 MENCAP and International Association of the Scientific Study of Intellectual and Developmental Disabilities and John Wiley \& Sons Ltd 
abilities in DS, by administering receptive and productive vocabulary tasks that vary in intrinsic STM processing demands and by using a verbal STM task minimising linguistic processing demands. We also assessed the role of selective attention and response inhibition that may influence performance in the PPVT receptive vocabulary tasks and which are affected in DS (Breckenridge et al. 2013; Costanzo et al. 2013). Selective attention is required to focus attention on the target picture information and to inhibit irrelevant picture information in the fourpicture array PPVT items; response inhibition is necessary to inhibit precipitated responses to nontarget pictures when making a response decision. If verbal STM is a true predictor of vocabulary abilities, then a specific association should be observed between the verbal STM measure and all vocabulary measures, and this after control of attentional and response inhibitory abilities.

\section{Methods}

For assessing receptive vocabulary, we selected the Évaluation du Vocabulaire en Images Peabody (EVIP) vocabulary scale (Dunn et al. I993), which is the French adaptation of the PPVT and is the most frequently used standardised vocabulary task in studies on language and STM abilities in DS. As vocabulary tasks with minimal STM demands, we selected single picture naming tasks; these tasks require retrieving a lexical entry for a single picture physically present during the entire task; no information has to be maintained in STM except for a minimal STM involvement during response monitoring. Productive vocabulary was assessed for a similar lexicon as for receptive vocabulary, by including pictures for frequent nouns, rare nouns and verbs taken from the standardised ISADYLE oral language assessment battery (Piérart et al. 2010). Verbal STM was assessed by using a previously validated serial order reconstruction task for word lists. This STM task minimised linguistic processing demands by using highly familiar verbal items, by representing the items at recall via picture cards and by requesting participants to reconstruct the serial order of the items within the memory list via picture cards (Majerus et al. 2006). At the same time, this task maximised serial order STM requirements that have been most consistently associated with vocabulary knowledge in previous studies in typically developing children (Majerus et al. 2006; Leclercq \& Majerus 20I0). Furthermore, given the speech output processing difficulties that characterise DS (Dodd \& Thompson 200I), this task allows for a valid assessment of STM performance as no verbal output is required. This task has been shown to predict both receptive vocabulary and novel word learning performance in typically developing children (Leclercq \& Majerus 20I0; Majerus \& Boukebza 2013). In order to determine the specificity of the association between vocabulary knowledge and verbal STM, we also administered a visuo-spatial STM task (Corsi block tapping task; Corsi 1972). Selective attention abilities were assessed using the 'faces' selective attention subtest from the NEPSY test battery (Korkman et al. 2003), and response inhibition abilities were assessed using the 'tapping test' motor response inhibition task (Gerstadt et al. I994).

\section{Participants}

Forty-seven participants (I 8 females) with DS were recruited for this study. Their age ranged between 18 and 43 years. The participants were selected from two sheltered workshops for people with intellectual disability in French-speaking Belgium and Switzerland. Twenty-two participants lived in their families; 17 participants lived in the institution during working days, and 8 participants were full-time residents of the institution. Oral consent was obtained from each participant, and written consent was obtained from the participants' legal guardians. The participants were tested in a quiet room in their institution. All participants had been screened for sensory and motor disabilities; I2 participants presented mild signs of motor disability, I I participants were wearing glasses, and 2 participants showed minor signs of auditory deficits. Participants were also screened for signs of dementia using the Dementia Screening Questionnaire (Deb et al. 2007; Beciani et al. 20I I) completed by referent caregivers; all participants performed below the cut-off score $(<20)$.

\section{Tasks}

\section{Receptive vocabulary knowledge}

Receptive vocabulary knowledge was assessed using the standardised EVIP vocabulary scale (Dunn et al.

(C) 2017 MENCAP and International Association of the Scientific Study of Intellectual and Developmental Disabilities and John Wiley \& Sons Ltd 
I), a French adaptation of the PPVT (Dunn \& Dunn I98I). In this test, participants hear a word spoken by the experimenter, and they have to select, among a choice of four pictures, the picture that matches the spoken word. Test administration is stopped after six erroneous responses on eight consecutive trials. As a dependent variable, the raw vocabulary score was retained for analysis. This task has a high test-retest reliability ( $R=0.80$; Dunn et al. I993).

Productive vocabulary knowledge

Productive vocabulary knowledge was assessed using the picture naming subtests of the standardised ISADYLE language assessment battery (Piérart et al. 20IO). Naming abilities for lexically frequent and concrete nouns were assessed via 52 pictures representing various concrete objects (animals, tools, clothes, body parts, man-made objects, food). Naming abilities for lexically infrequent nouns were assessed via 25 pictures depicting man-made objects (e.g. latch). Naming abilities for verbs were assessed via I3 pictures depicting various actions (e.g. to cut, to lick). For each task, a score of 2 was given when the correct lexical target was produced, a score of I was given for an approximating response (e.g. train for locomotive), and a score of o was given for an incorrect response or a no response. The participants' responses were not penalised for phonetic deviations due to articulatory difficulties. The three measures have a high reliability (Cronbach $\alpha: 0.92,0.86$ and 0.7I, respectively; Piérart et al. 2010).

\section{Verbal short-term memory}

The verbal STM task developed by Majerus et al. (2006) measured the ability to maintain serial order information in verbal STM. After the auditory presentation of sequences of animal names ['chat', 'chien', 'coq', 'lion', 'loup', 'ours' and 'singe' (cat, dog, cock, lion, wolf, bear and monkey, respectively)], the participants needed to rearrange cards depicting the animals as a function of their order of presentation. The seven stimuli were used to form lists with lengths ranging from two to seven items, and there were four trials for each list length. The sequences had been recorded by a female voice at a rate of one item per second, stored on computer disk and were presented to the participant via headphones and by increasing list length. The participant was told the following story for task description: "Every year, the animals from all over the world gather to have a huge race. This year, seven animals are participating: a dog, a cat, a lion, a bear, a wolf, a monkey and a cock [the experimenter shows the cards of the corresponding animals]. Several races take place. Sometimes, only two animals are participating. Sometimes, there are three, four or five animals. On other times, there are big races with six or seven animals. Through the headphones, you will hear someone announce the animals' order of arrival at the finish line, from the first to the last animal. Immediately after, you have to put the pictures of the animals on the podium in their order of arrival. The animal arriving first has to be put on the highest step and the last one on the lowest step, ok?" The participant was informed when list length increased. A pre-task assessment confirmed that all participants were able to correctly recognise and name the pictures on the cards. The trials of length 2 were practice trials in order to further familiarise the participants with task requirements and the auditory word-picture mappings; these trials had to be completed successfully before starting the experimental trials; performance on trials of length 2 was not considered for the final score. The total number of correct trials, by pooling over sequence lengths 3 to 7, was retained for analysis. This task has a high test-retest reliability $(R=0.82$; Majerus et al. 2006).

Visuo-spatial short-term memory

Visuo-spatial short-term memory was assessed using the Corsi block tapping task (Corsi I972). This task involves the reproduction by the participant of visuo-spatial sequences of increasing length, by touching two to nine wooden blocks fixed on a board and randomly distributed over the surface of the board. The sequences were first performed by the experimenter; next, the participant had to reproduce the sequence. There were three trials for each sequence length, and testing was stopped when less than two trials for a given sequence length were correctly reproduced. The total number of correct trials, by pooling over all sequence lengths, was retained for analysis. This task has a high reliability (Cronbach $\alpha=0.85$; Mammarella et al. 2006). 
S. Majerus \& K. Barisnikov • Down syndrome STM

\section{Selective attention}

Selective attention was tested using the faces subtest of the NEPSY standardised neuropsychology test battery (Korkman et al. 2003). This test involves the detection of two target faces among eight arrays of 12 faces. The participants have to cross as many target faces as possible within $\mathrm{I} 80 \mathrm{~s}$. We retained the precision score (number of hits minus false alarms) for analysis. This task has a good test-retest reliability $(R=0.76)$.

\section{Response inhibition}

Motor response inhibition was measured using an adapted version of the tapping test (Gerstadt et al. I994; Barisnikov \& Hippolyte 20I I). The task includes three series of eight trials presented in pseudorandom order. For each trial, the experimenter taps either once or twice a wooden dowel $(22.5 \mathrm{~cm}$ long, $2.5 \mathrm{~cm}$ in diameter) on the desk and then hands it to the child, who has to do the opposite number of taps. We retained the number of correct responses over the three trial series for analysis. This task has a good test-retest reliability $(R=0.78)$ (Barisnikov \& Hippolyte 20II).

\section{Non-verbal intelligence}

General non-verbal intellectual efficiency was measured using the Raven's progressive coloured matrices (Raven et al. I998). Raw scores were retained for further analysis. This task has a high reliability (Cronbach $\alpha=0.88-0.93$; Abdel-Khalek 2005).

\section{Task order}

The different tasks were administered in pseudorandom order in three sessions, lasting each about $25 \mathrm{~min}$.

\section{Statistical analyses}

Data were analysed using Bayesian regression analysis (Love et al. 2015) which allows for an unbiased estimation (relative to frequentist statistics) of the predictive evidence for different explanatory variables, against the null model (Wagenmakers 2007). Bayesian regression analysis determines the model (combination of predictor variables) associated with the largest evidence given the data. The bigger the
Bayes factor $(\mathrm{BF})$, the stronger the evidence in favour of the corresponding model against the null model. A $\mathrm{BF}>3$ provides moderate evidence; $\mathrm{BF}>\mathrm{IO}$ provides strong evidence, and a $\mathrm{BF}>30$ provides very strong evidence (Lee \& Wagenmakers 20I4). We used the JASP Bayesian statistics software package (Love et al. 20I5; https://jasp-stats.org/). We present the BF value of the model(s) associated with the strongest evidence and specific Bayesian effect values for each predictor variable $(\mathrm{BF}$ forward $=$ comparison of the model with the effect against the null model; $\mathrm{BF}$ backward = comparison of the largest model with the effect against the same model that excludes the effect).

\section{Results}

Descriptive statistics are shown in Table I. The frequent productive vocabulary measure was characterised by a strong negative skew, indicating a large number of scores close to the maximum; nearly half of the sample (20 participants) had scores ranging between 94 and I04, corresponding to alexical age estimated between 9 and I I years (Piérart et al. 2010). For this reason, this vocabulary measure was not further used in the regression analyses, except for the final analyses using a pooled productive vocabulary score (see below).

\section{Correlation analyses}

Age-corrected correlations and confidence intervals are reported in Table 2. Performance on Raven's matrices showed a significant association with all other measures, except for the verb productive vocabulary measure. The receptive vocabulary measure showed moderate to strong correlations with all productive vocabulary measures, as well as with the STM, selective attention and response inhibition measures. The productive vocabulary measures yielded very strong intercorrelations, but they showed weaker or no associations with the STM, selective attention and response inhibition measures. The selective attention measure showed correlations of moderate size with most measures, except for the verb productive vocabulary measure and the verbal STM measure. Finally, the response inhibition measure showed moderate to strong correlations with all measures necessitating a manual response and a choice between several competing responses.

(C) 2017 MENCAP and International Association of the Scientific Study of Intellectual and Developmental Disabilities and John Wiley \& Sons Ltd 
S. Majerus \& K. Barisnikov • Down syndrome STM

Table I Descriptive statistics for all tasks

\begin{tabular}{|c|c|c|c|c|}
\hline & Mean & Standard deviation & Skewness ${ }^{\dagger}$ & Kurtosis \\
\hline Age & 31.67 & 7.89 & -0.42 & -1.10 \\
\hline Raven's CPM raw score (standard score) & I5.89 (57.77) & $5.56(12.28)$ & 0.08 & -1.09 \\
\hline EVIP raw score (vocabulary age) & $69.83(6.49)$ & $23.99(2.12)$ & 0.09 & -0.66 \\
\hline \multicolumn{5}{|l|}{ Productive vocabulary } \\
\hline Frequent $(\max =104)$ & 86.66 & 13.04 & -1.49 & 2.22 \\
\hline Rare $(\max =50)$ & 21.62 & 10.94 & 0.06 & -0.43 \\
\hline Verbs $(\max =26)$ & 15.36 & 5.24 & -0.34 & -0.53 \\
\hline \multicolumn{5}{|l|}{ Short-term memory } \\
\hline Visuo-spatial $(\max =54)$ & 17.49 & $12.5 \mid$ & 0.33 & -1.22 \\
\hline Verbal $(\max =20)$ & 5.87 & 3.93 & 0.60 & 0.08 \\
\hline Selective attention - precision & 2.62 & 6.99 & 0.10 & -0.32 \\
\hline Response inhibition $(\max =24)$ & 16.04 & 8.34 & -0.73 & -0.87 \\
\hline
\end{tabular}

${ }^{\dagger}$ Standard error skewness cut-off $= \pm 0.70$.

${ }^{\ddagger}$ Standard error Kurtosis cut-off $= \pm 1.39$.

Table 2 Correlations between all measures (after control of age) and $95 \%$ confidence intervals

\begin{tabular}{|c|c|c|c|c|c|c|c|c|}
\hline & EVIP & $\begin{array}{c}\text { Voc. prod. } \\
\text { frequent }\end{array}$ & $\begin{array}{l}\text { Voc. prod. } \\
\text { rare }\end{array}$ & $\begin{array}{l}\text { Voc. prod. } \\
\text { verbs }\end{array}$ & $\begin{array}{c}\text { Visuo-spatial } \\
\text { STM }\end{array}$ & $\begin{array}{l}\text { Verbal } \\
\text { STM }\end{array}$ & $\begin{array}{l}\text { Selective } \\
\text { attention }\end{array}$ & $\begin{array}{l}\text { Response } \\
\text { inhibition }\end{array}$ \\
\hline \multirow[t]{2}{*}{ Raven's matrices } & $0.50 * * *$ & $0.35 *$ & $0.38 *$ & 0.26 & $0.47 * *$ & $0.63 * * *$ & $0.4 I^{* *}$ & $0.34 *$ \\
\hline & $0.25-0.71$ & $-0.03-0.60$ & $0.07-0.60$ & $-0.04-0.54$ & $0.22-0.69$ & $0.42-0.79$ & $0.16-0.61$ & $0.01-0.6 \mathrm{I}$ \\
\hline \multirow[t]{2}{*}{ EVIP } & - & $0.44 * *$ & $0.61 * * *$ & $0.53 * * *$ & $0.38 * *$ & $0.61 * * *$ & $0.43^{* *}$ & $0.42 * *$ \\
\hline & & $0.19-66$ & $0.35-0.79$ & $0.22-0.75$ & $0.09-0.63$ & $0.4 \mid-0.78$ & $0.15-0.69$ & $0.18-0.65$ \\
\hline \multirow[t]{2}{*}{ Voc. prod. frequent } & & - & $0.65 * * *$ & $0.62 * * *$ & 0.29 & 0.28 & $0.39 * *$ & 0.28 \\
\hline & & & $0.50-0.78$ & $0.44-0.79$ & $-0.10-0.55$ & $-0.01-0.52$ & $0.09-0.63$ & $0.06-0.53$ \\
\hline \multirow[t]{2}{*}{ Voc. prod. rare } & & & - & $0.77 * * *$ & 0.20 & $0.34^{*}$ & $0.30 *$ & 0.24 \\
\hline & & & & $0.64-0.85$ & $-0.1|-0.5|$ & $0.08-0.59$ & $-0.01-0.57$ & $-0.03-0.50$ \\
\hline \multirow{2}{*}{ Voc. prod. verbs } & & & & - & 0.08 & $0.37 *$ & 0.12 & 0.20 \\
\hline & & & & & $-0.21-0.42$ & $0.06-0.64$ & $-0.18-0.41$ & $-0.10-0.47$ \\
\hline \multirow[t]{2}{*}{ Visuo-spatial STM } & & & & & - & $0.60 * * *$ & $0.43 * *$ & $0.63 * * *$ \\
\hline & & & & & & $0.40-0.78$ & $0.15-0.66$ & $0.49-0.76$ \\
\hline \multirow[t]{2}{*}{ Verbal STM } & & & & & & - & 0.27 & $0.53 * * *$ \\
\hline & & & & & & & $0.0 \mathrm{I}-0.54$ & $0.33-0.70$ \\
\hline \multirow[t]{2}{*}{ Selective attention } & & & & & & & - & $0.34^{*}$ \\
\hline & & & & & & & & $0.06-0.56$ \\
\hline
\end{tabular}

$95 \%$ confidence intervals estimated by a bootstrap procedure with rooo samples (Efron \& Tibshirani 1993).

${ }^{*} P<0.05$.

$* * P<0.01$.

$* * * P<0.001$

\section{Bayesian regression analyses}

Dependent variable: receptive vocabulary (Évaluation du Vocabulaire en Images Peabody)

Bayesian linear regression analysis determined the specificity of the association between receptive vocabulary and verbal STM scores, relative to all other predictor measures (Table 3). The combination of predictor variables associated with the highest $\mathrm{BF}_{\mathrm{IO}}$ against the null model was a model including the verbal STM measure and the selective attention measure $\left(\mathrm{BF}_{\mathrm{IO}}=2655 \mathrm{I}\right)$; this model was 3.2 times

(C) 2017 MENCAP and International Association of the Scientific Study of Intellectual and Developmental Disabilities and John Wiley \& Sons Ltd 
S. Majerus \& K. Barisnikov • Down syndrome STM

Table 3 Bayesian regression analysis for the receptive vocabulary measure EVIP: analysis of effects

\begin{tabular}{lccccccc}
\hline Effects & $\boldsymbol{P}$ (incl) & $\boldsymbol{P}$ (incl|data) & $\mathbf{B F}_{\text {inclusion }}$ & $\mathbf{B F}_{\text {backward }}$ & \% errorB & $\mathbf{B F}_{\text {forward }}$ & \% errorF \\
\hline Age & 0.500 & 0.221 & 0.284 & 0.354 & 0.002 & 0.886 & $5.407 \mathrm{e}-5$ \\
Raven & 0.500 & 0.288 & 0.405 & 0.424 & 0.002 & 218.477 & $7.129 \mathrm{e}-4.001$ \\
Response inhibition & 0.500 & 0.263 & 0.356 & 0.492 & 0.002 & 21.028 & \\
Selective attention & 0.500 & 0.737 & 2.796 & 2.207 & 0.002 & 27.736 & $9.510 \mathrm{e}-4.004$ \\
Visuo-spatial STM & 0.500 & 0.256 & 0.344 & 0.572 & 0.002 & 10.865 & \\
Verbal STM & 0.500 & 0.975 & 38.908 & 10.418 & 0.004 & 7946.553 & $4.272 \mathrm{e}-5$ \\
\hline
\end{tabular}

more likely as the model with the next highest $\mathrm{BF}_{\mathrm{IO}}$ $\left(\mathrm{BF}_{\mathrm{IO}}=8294 ;\right.$ model including the verbal STM, selective attention and visuo-spatial STM measures). An analysis of specific effects showed that the verbal STM measure was the predictor associated with the largest evidence, whether compared only with the null model $\left(\mathrm{BF}_{\text {forward }}=7947\right)$ or whether compared with all other predictor variables $\left(\mathrm{BF}_{\text {backward }}=\mathrm{IO}\right)$

(Table 3). The verbal STM measure explained II \% of specific variance of vocabulary scores.

Dependent variable: productive vocabulary - rare nouns

When predicting the productive vocabulary measure for rare nouns measure by the same predictor measures, Bayesian regression analysis showed that none of the 64 possible models exceeded a $\mathrm{BF}_{\mathrm{IO}}$ of 3 against the null model. Analysis of effects showed that the variable associated with the largest evidence was non-verbal intellectual efficiency $\left(\mathrm{BF}_{\text {forward }}=2 . \mathrm{I} 2\right.$; $\left.\mathrm{BF}_{\text {backward }}=0.8 \mathrm{I}\right)$, but the evidence for these effects was anecdotal (Table 4).

Dependent variable: productive vocabulary - verbs

For the verb productive vocabulary measure, the model associated with the strongest evidence included only the verbal STM variable; however, the $\mathrm{BF}_{\mathrm{IO}}$ was small $\left(\mathrm{BF}_{\mathrm{IO}}=\mathbf{2 . 7 0}\right)$, as confirmed by an analysis of specific effects $\left(\mathrm{BF}_{\text {forward }}=2.70\right.$; $\mathrm{BF}_{\text {backward }}=2.35$ ) (Table 5). In sum, like in the preceding analysis, there was no conclusive evidence for any specific association between verbal STM and productive vocabulary.

Finally, we examined to what extent the receptive and productive vocabulary measures both provided a valid estimate of vocabulary knowledge. First, it should be noted that the receptive and productive vocabulary scales showed large, age-corrected correlations (Table 2). The correlations between receptive and productive vocabulary measures were still strong when additionally correcting for nonverbal intelligence (verbs, $r_{\text {partial }}=0.53$; rare nouns: $r_{\text {partial }}=0.48$ ). This indicates that the productive and receptive vocabulary tasks measured similar lexical abilities. Also, we checked whether structural differences such as the separation of lexical categories in the productive measures and the mixing of lexical categories in the receptive measures could have biased the results, by pooling the different productive (frequent and rare nouns, verbs) measures together. The model with the highest $\mathrm{BF}_{\text {Io }}$ included only the non-verbal intelligence measure $\left(\mathrm{BF}_{\mathrm{IO}}=4 \cdot 32\right)$

Table 4 Bayesian regression analysis for productive vocabulary for rare nouns: analysis of effects

\begin{tabular}{lccccccc}
\hline Effects & $\boldsymbol{P}$ (incl) & $\boldsymbol{P}$ (incl|data) & $\mathbf{B F}_{\text {inclusion }}$ & $\mathbf{B F}_{\text {backward }}$ & \% error & $\mathbf{B F}_{\text {forward }}$ & $\%$ errorF \\
\hline Age & 0.500 & 0.488 & 0.952 & 1.440 & $8.660 \mathrm{e}-4$ & 0.336 & $8.178 \mathrm{e}-6$ \\
Raven & 0.500 & 0.535 & 1.149 & 0.807 & $8.958 \mathrm{e}-4$ & 2.122 & $6.134 \mathrm{e}-5$ \\
Response inhibition & 0.500 & 0.345 & 0.526 & 0.575 & $8.951 \mathrm{e}-4$ & 0.726 & $4.459 \mathrm{e}-5$ \\
Selective attention & 0.500 & 0.453 & 0.827 & 0.878 & $8.940 \mathrm{e}-4$ & 1.226 & $6.232 \mathrm{e}-5$ \\
Visuo-spatial STM & 0.500 & 0.320 & 0.470 & 0.662 & $8.968 \mathrm{e}-4$ & 0.516 & $2.063 \mathrm{e}-5$ \\
Verbal STM & 0.500 & 0.472 & 0.895 & 0.736 & $8.968 \mathrm{e}-4$ & 1.738 & $6.332 \mathrm{e}-5$ \\
\hline
\end{tabular}

(C) 2017 MENCAP and International Association of the Scientific Study of Intellectual and Developmental Disabilities and John Wiley \& Sons Ltd 
S. Majerus \& K. Barisnikov • Down syndrome STM

Table 5 Bayesian regression analysis for productive vocabulary for verbs: analysis of effects

\begin{tabular}{|c|c|c|c|c|c|c|c|}
\hline Effects & $P$ (incl) & $P$ (incl|data) & $\mathbf{B F}_{\text {inclusion }}$ & $\mathbf{B F}_{\text {backward }}$ & $\%$ errorB & BF $_{\text {forward }}$ & $\%$ errorF \\
\hline Age & 0.500 & 0.399 & 0.663 & 0.871 & 0.012 & 0.313 & $1.766 e-5$ \\
\hline Raven & 0.500 & 0.352 & 0.544 & 0.549 & 0.012 & 0.730 & $4.488 e-5$ \\
\hline Response inhibition & 0.500 & 0.339 & 0.512 & 0.615 & 0.012 & 0.532 & $2.309 e-5$ \\
\hline Selective attention & 0.500 & 0.311 & 0.451 & 0.557 & 0.012 & 0.350 & $4.490 e-6$ \\
\hline Visuo-spatial STM & 0.500 & 0.443 & 0.795 & 1.295 & 0.012 & 0.309 & $1.944 e-5$ \\
\hline Verbal STM & 0.500 & 0.740 & 2.851 & 2.350 & 0.012 & 2.701 & $5.736 e-5$ \\
\hline
\end{tabular}

followed by a model including the verbal STM and the selective attention measures $\left(\mathrm{BF}_{\mathrm{IO}}=4.08\right)$. As shown by the specific effect analysis, evidence for inclusion of the verbal STM measure remained low $\left(\mathrm{BF}_{\text {forward }}=3.26, \mathrm{BF}_{\text {backward }}=0.7 \mathrm{I}\right)($ Table 6$)$.

\section{Discussion}

This study aimed at exploring the association between vocabulary knowledge and verbal STM abilities in participants with DS. By distinguishing receptive and productive vocabulary measures, we observed that verbal STM abilities were strongly associated with a standardised measure of receptive vocabulary knowledge, while showing no specific association with productive vocabulary measures after control of nonverbal intellectual efficiency.

These results show that the type of task selected for testing vocabulary knowledge is critical when addressing associations between STM and vocabulary abilities in DS. One could argue that receptive vocabulary tasks are more sensitive measures of vocabulary knowledge than productive tasks.

Receptive vocabulary measures typically assess lexical knowledge for a large number of items from diverse semantic fields and syntactic categories and include items of a relatively low lexical frequency (e.g. hook, bark). Verbal STM may be particularly important for accurate encoding and learning of words that are encountered only a few times. This is however not in line with our data as there was no specific association between STM performance and the productive vocabulary measures that also assessed knowledge for rare words. Rather, a major difference between receptive and productive vocabulary tasks is, as noted before, the intrinsic STM load. In multi-picture receptive vocabulary tasks such as the PPVT/EVIP, participants need to maintain the auditory form of the target word in STM, while analysing up to four pictures, activating the lexical and semantic representations corresponding to each picture and comparing these with the auditory word form maintained in STM. These STM demands are further increased by the inferential thinking abilities that are necessary for matching the pictures and the auditory target word for a number of items (e.g. the word 'adjustable' is represented by the target picture of a belt in the EVIP) (Shah \& Miyake I996; Pérez et al. 20I4). These STM demands are absent in the productive vocabulary measures we used as a single

Table 6 Bayesian regression analysis for the pooled productive vocabulary score: analysis of effects

\begin{tabular}{|c|c|c|c|c|c|c|c|}
\hline Effects & $P$ (incl) & $P$ (incl|data) & $\mathbf{B F}_{\text {inclusion }}$ & BF $_{\text {backward }}$ & $\%$ errorB & $\mathbf{B F}_{\text {forward }}$ & $\%$ errorF \\
\hline Age & 0.500 & 0.351 & $0.54 I$ & 0.771 & 0.001 & 0.291 & $3.058 e-5$ \\
\hline Raven & 0.500 & 0.524 & 1.103 & 0.742 & 0.001 & 4.322 & 0.011 \\
\hline Response inhibition & 0.500 & 0.362 & 0.568 & 0.597 & 0.001 & 1.331 & $6.318 e-5$ \\
\hline Selective attention & 0.500 & 0.535 & I.152 & 1.097 & 0.001 & 2.977 & $5.54 l e-5$ \\
\hline Visuo-spatial STM & 0.500 & 0.311 & 0.452 & 0.602 & 0.001 & 0.895 & $5.446 e-5$ \\
\hline Verbal STM & 0.500 & 0.479 & 0.918 & 0.705 & 0.001 & 3.255 & $5.35 \mathrm{le}-5$ \\
\hline
\end{tabular}

(C) 2017 MENCAP and International Association of the Scientific Study of Intellectual and Developmental Disabilities and John Wiley \& Sons Ltd 
lexical item has to be retrieved for a single picture. Finally, it could be argued that verbal STM is involved in the acquisition of auditory word forms, which are measured by receptive vocabulary tasks, but that these input lexical representations are not sufficient to also guarantee precise retrieval and production in a naming task. This is however unlikely given that a large number of studies have shown an association between verbal STM abilities and learning of novel output word forms, including studies that used the same serial order reconstruction STM task as used in this study (Papagno et al. I99I; Gupta 2003; Jarrold et al. 2009; Majerus \& Boukebza 2013). In any case, the results of this study urge us to be cautious when estimating vocabulary knowledge and its associations with verbal STM based on a single type of vocabulary measure. Receptive vocabulary measures with minimal intrinsic STM requirements need to be developed, such as single picture-auditory word judgement tasks, and associations between verbal STM capacity and estimates of vocabulary knowledge obtained from this novel type of receptive vocabulary tasks need to be studied.

The consideration of the intrinsic STM load of receptive vocabulary tasks may be particularly relevant in the case of participants with DS who have typically very low verbal STM abilities, their digit spans rarely exceeding three items (Jarrold et al. 2002; Iacono et al. 2010). Given the amount of information that needs to be activated and maintained in a wordpicture matching task such as the EVIP and PPVT, it could be the case that the verbal STM limitations prevent individuals with DS from showing their full lexical knowledge. This is in line with the observation, in our participant sample, of a lower receptive vocabulary age ( 7.2 years) even for participants performing at ceiling on the productive vocabulary measure (estimated productive vocabulary age: 9I I years). At the same time, our findings may not be specific to DS, given that the same argumentation can also be applied to the large set of studies that have investigated the association between receptive vocabulary development and verbal STM in typically developing populations, as these studies also used the PPVT/EVIP multi-picture vocabulary task (e.g.

Gathercole et al. I992; Naess et al. 2015; Majerus et al. 2006; Leclercq \& Majerus 2010). For typically developing populations, studies exploring STM/vocabulary associations with productive vocabulary tasks that have no intrinsic STM load are lacking and need urgently need to be conducted; existing studies exploring the role of STM in productive lexical measures used novel word learning tasks that also have an intrinsic STM load (e.g. Majerus \& Boukebza 20I3). The results of this study raise the possibility that the association between verbal STM and receptive vocabulary measures observed in different populations may reflect a role of STM in task performance and not (only) in vocabulary acquisition per se.

A final question is whether the results observed in this study may have been affected by the fact that all participants were adults. It is important to note that studies in typically developing teenagers and adults have observed significant associations between verbal STM and receptive vocabulary, although this link is reduced relative to young children (e.g. Gathercole et al. I999; Majerus et al. 2008). Moreover, the participants with DS in the present study had a receptive lexical age (mean 6.5 years) at which reliable associations between verbal STM and vocabulary knowledge are generally observed (e.g. Majerus et al. 2006; Majerus \& Boukebza 20I3). Given the large room for increase of lexical knowledge, and the slowed development of language abilities in DS, adult samples should still be informative about the association of verbal STM abilities and lexical development (Iacono et al. 2010). At the same time, the generality of the findings of this study needs to be examined in younger individuals with DS, even if this may prove difficult given the very low verbal STM abilities in young children with DS (Broadley et al. I995).

To conclude, this study showed a dissociation between productive and receptive vocabulary measures when exploring the link between verbal STM abilities and vocabulary knowledge in DS. The strong and selective association observed between verbal STM and receptive but not productive vocabulary measures indicates that verbal STM is not generally associated with vocabulary abilities in DS, but may reflect task-specific factors and STM load associated with receptive vocabulary measures.

\section{Acknowledgements}

This study was supported by grant IUAP P7/I I from the Belgian Federal Science Policy administration

(C) 2017 MENCAP and International Association of the Scientific Study of Intellectual and Developmental Disabilities and John Wiley \& Sons Ltd 
and by grant T.I003.I5 from the Fund for Scientific Research FNRS (Belgium) awarded to the first author and by grant I000I4-I20657/I from the Swiss National Science Foundation awarded to the second author. We thank all the adults, parents and caregivers for their collaboration and their time devoted to this study. We also thank Jean-Jacques Detraux, Loise Hippolyte and Géraldine Vrancken for their help in participant recruitment and testing.

\section{References}

Abdel-Khalek A. M. (2005) Reliability and factorial validity of the standard progressive matrices among Kuwaiti children ages 8 to I5 years. Perceptual and Motor Skills IoI, 409-I2. https://doi.org/I0.2466/pms.IOI.2.409-4I2.

Avons S. E., Wragg C. A., Cupples L. \& Lovegrove W. J. (1998) Measures of phonological short-term memory and their relationship to vocabulary development. Applied PsychoLinguistics 19, 583-60I.

Baddeley A., Gathercole S. \& Papagno C. (I998) The phonological loop as a language learning device. Psychological Review I05, I58-73.

Barisnikov K. \& Hippolyte L. (20II) Batterie d'évaluation de la cognition sociale et émotionnelle. In: Théorie de l'esprit: Entre cognition, émotion et adaptation sociale chez des personnes typiques et atypiques (ed. N. Nader-Grosbois), pp. 135-5I. DeBoeck, Bruxelles.

Beciani S., Vetro E., Barisnikov K., Detraux J.-J. \& Van der Linden M. (20II) Elaboration d'une batterie d'évaluation des signes de vieillissement dans la trisomie 21. Revue Francophone de la Déficience Intellectuelle 22, I29-40.

Breckenridge K., Braddick O., Anker S., Woodhouse M. \& Atkinson J. (2013) Attention in Williams syndrome and Down's syndrome: performance on the new early childhood attention battery. British fournal of Developmental Psychology 3I, 257-69. https://doi.org/ IO.IIII/bjdp.I2003.

Broadley I., MacDonald J. \& Buckley S. (I995) Working memory in children with Down syndrome. Down's Syndrome, Research and Practice 3, 3-8.

Brock J. \& Jarrold C. (2004) Language influences on verbal short-term memory performance in Down syndrome: item and order recognition. Fournal of Speech, Language, and Hearing Research 47, 1334-46.

Brock J. \& Jarrold C. (2005) Serial order reconstruction in Down syndrome: evidence for a selective deficit in verbal short-term memory. Fournal of Child Psychology and Psychiatry 46, 304-I6. https://doi.org/IO.IIII/j.I4697610.2004.00352.x.

Chapman R. S. (2003) Language and communication in individuals with Down syndrome. In: International Review of Research in Mental Retardation: Language and
Communication (ed. L. Abbeduto), vol. 27, pp. I-34. San Diego: Academic Press.

Chapman R. S., Hesketh L. J. \& Kistler D. J. (2002) Predicting longitudinal change in language production and comprehension in individuals with Down syndrome: hierarchical linear modeling. Fournal of Speech, Language, and Hearing Research 45, 902-15.

Chapman R. S., Sindberg H., Bridge C., Gigstead K. \& Hesketh L. (2006) Effect of memory support and elicited production on fast mapping of new words by adolescents with Down syndrome. Fournal of Speech, Language, and Hearing Research 49, 3-I5. https://doi.org/I0.1044/10924388(2006/00I).

Corsi P. M. (I972). Human memory and the medial temporal region of the brain. McGill University, Montréal: Unpublished thesis.

Costanzo F., Varuzza C., Menghini D., Addona F., Gianesini T. \& Vicari S. (20I3) Executive functions in intellectual disabilities: a comparison between Williams syndrome and Down syndrome. Research in Developmental Disabilities 34, I770-80. https://doi.org/10.1016/j. ridd.2013.01.024.

Deb S., Hare M., Prior L. \& Bhaumik S. (2007) Dementia screening questionnaire for individuals with intellectual disabilities. The British fournal of Psychiatry I90, 440-4.

Dodd B. \& Thompson L. (200I) Speech disorder in children with Down's syndrome. Fournal of Intellectual Disability Research 45, 308-16.

Dunn L. M. \& Dunn L. M. (198I) Peabody Picture Vocabulary Test-Revised: Manual for Forms $L$ and $M$. American Guidance Service, Circle Pines, MN.

Dunn L. M., Thériault-Whalen C. M. \& Dunn L. M. (1993) Echelle de vocabulaire en images Peabody. Adaptation française du Peabody Picture Vocabulary Test. Psycan, Toronto, Canada.

Efron B., \& Tibshirani R. J. (1993) An introduction to the bootstrap. New York: Chapman and Hall.

Gathercole S. E., Frankish C. R., Pickering S. J. \& Peaker S. (1999) Phonotactic influences on short-term memory. fournal of Experimental Psychology: Human Learning and Memory 25, 84-95.

Gathercole S. E., Hitch G. J., Service E., \& Martin A. J. (1997) Phonological short-term memory and new word learning in children. Developmental Psychology 33, 966-79.

Gathercole S. E., Service E., Hitch G. J., Adams A. M. \& Martin A. J. (1999) Phonological short-term memory and vocabulary development: further evidence on the nature of the relationship. Applied Cognitive Psychology i3, 65-77.

Gathercole S. E., Willis C. S., Baddeley A. D. \& Emslie H. (1994) The children's test of nonword repetition: a test of phonological working memory. Memory 2, I03-27.

Gathercole S. E., Willis C. S., Emslie H. \& Baddeley A. D. (I992) Phonological memory and vocabulary

(C) 2017 MENCAP and International Association of the Scientific Study of Intellectual and Developmental Disabilities and 
S. Majerus \& K. Barisnikov • Down syndrome STM

development during the early school years: a longitudinal study. Developmental Psychology 28, 887-98.

Gerstadt C. L., Hong Y. J. \& Diamond A. (1994) The relationship between cognition and action: performance of children 3 I/2-7 years old on a Stroop-like day-night test. Cognition 53, I29-53.

Gupta P. (2003) Examining the relationship between word learning, nonword repetition and immediate serial recall in adults. Quarterly fournal of Experimental Psychology 56A, I213-36.

Hick R. F., Botting N. \& Conti-Ramsden G. (2005) Shortterm memory and vocabulary development in children with Down syndrome and children with specific language impairment. Developmental Medicine and Child Neurology 47, 532-8.

Hulme C., Maughan S. \& Brown G. D. (I99I) Memory for familiar and unfamiliar words: evidence for a long-term memory contribution to short-term memory span. fournal of Memory and Language 30, 685-701.

Iacono T., Torr J. \& Wong H. Y. (2010) Relationships amongst age, language and related skills in adults with Down syndrome. Research in Developmental Disabilities 3I, 568-76. https://doi.org/I0.I0I6/j.ridd.2009.12.009.

Jarrold C., Baddeley A. D. \& Phillips C. E. (2002) Verbal short-term memory in Down syndrome: a problem of memory, audition, or speech? Fournal of Speech, Language, and Hearing Research 45, 53I-44.

Jarrold C., Thorn A. \& Stephens E. (2009) The relationships among verbal short-term memory, phonological awareness, and new word learning: evidence from typical development and Down syndrome. Fournal of Experimental Child Psychology 102, 196-2 18.

Korkman M., Kirk U. \& Kemp S. (2003) NEPSY—Bilan neuropsychologique de l'enfant. Editions du Centre de Psychologie Appliquée, Paris.

Laws G. \& Gunn D. (2004) Phonological memory as a predictor of language comprehension in Down syndrome: a five-year follow-up study. Fournal of Child Psychology and Psychiatry 45, 326-37.

Leclercq A. L. \& Majerus S. (2010) Serial order short-term memory predicts vocabulary development: evidence from a longitudinal study. Developmental Psychology 46, 4I7-27.

Lee M. D. \& Wagenmakers E.-J. (2014) Bayesian cognitive modeling: a practical course. Cambridge University Press, Cambridge.

Love J., Selker R., Marsman M., Jamil T., Dropmann D., Verhagen A. J. et al. (2015). JASP (Version 0.7).

Majerus S. (2013) Language repetition and short-term memory: an integrative framework. Frontiers in Human Neuroscience 7, 357. https://doi.org/I0.3389/ fnhum.2013.00357.

Majerus S. \& Boukebza C. (2013) Short-term memory for serial order supports vocabulary development: new evidence from a novel word learning paradigm. fournal of Experimental Child Psychology Ir6, 8I I-28.

Majerus S., Poncelet M., Greffe C. \& Van der Linden M. (2006) Relations between vocabulary development and verbal short-term memory: the importance of short-term memory for serial order information. Fournal of Experimental Child Psychology 93, 95-II9.

Majerus S., Poncelet M., Van der Linden M. \& Weekes B. S. (2008) Lexical learning in bilingual adults: the relative importance of short-term memory for serial order and phonological knowledge. Cognition 107, 395-419. https:// doi.org/I0.1016/j.cognition.2007.10.00318036515.

Mammarella I. C., Pazzaglia F. \& Cornoldi C. (2006) The assessment of imagery and visuo-spatial working memory functions in children and adults. In: Imagery and Spatial Cognition: Methods, models and cognitive assessment (eds T. Vecchi \& G. Bottini), pp. 15-38. John Benjamins, Amsterdam.

Mosse E. K. \& Jarrold C. (20II) Evidence for preserved novel word learning in Down syndrome suggests multiple routes to vocabulary acquisition. Fournal of Speech, Language, and Hearing Research 54, II37-52. https://doi. org/10.1044/1092-4388(2010/09-0244).

Naess K. A., Lervaag A., Lyster S. A. \& Hulme C. (2015) Longitudinal relationships between language and verbal short-term memory skills in children with Down syndrome. Fournal of Experimental Child Psychology 135, 43-55. https://doi.org/I0.IOI6/j.jecp.2015.02.004.

Papagno C., Valentine T. \& Baddeley A. D. (I99I) Phonological short-term memory and foreign-language vocabulary learning. Fournal of Memory and Language 30, 33I-47.

Pérez A. I., Paolieri D., Mazico P. \& Bajo T. (2014) The role of working memory in inferential sentence comprehension. Cognitive Processing 15, 405-13.

Piérart B., Comblain A., Grégoire J. \& Mousty P. (2010) Batterie ISADYLE. Solal, Marseille.

Raven J. C., Court J. H. \& Raven J. (1998) Progressive Matrices Couleur. Les Editions du Centre de Psychologie Appliquée, Paris.

Service E. (1992) Phonology, working memory, and foreignlanguage learning. Quarterly fournal of Experimental Psychology: Human Experimental Psychology 45A, 2I-50.

Shah P. \& Miyake A. (1996) The separability of working memory resources for spatial thinking and language processing: an individual differences approach. Fournal of Experimental Psychology. General 125, 4-27.

Wagenmakers E.-J. (2007) A practical solution to the pervasive problem of $\mathrm{p}$ values. Psychonomic Bulletin and Review I4, 779-804.

Accepted II October 2017 